\title{
CRISIS MANAGEMENT IN SMALL AND MEDIUM SCALE ENTERPRISES: A SYSTEMATIC LITERATURE REVIEW
}

\author{
*K.K.N.B. Adikaram \\ Department of Multidisciplinary Studies \\ University of Ruhuna \\ nilanthiadikaram@gmail.com \\ H.A.K.N.S. Surangi \\ Department of Commerce and Financial Management \\ University of Kelaniya \\ surangins@kln.ac.lk
}

\begin{abstract}
The study presents the findings of a systematic literature review of crisis management in Small and Medium Scale Enterprises (SMEs) referring to recent literature. Crisis management studies have received significant attention in academic research. This can also be observed in organizational crisis management. Compared to larger organizations, the attention received for SMEs was inadequate. Recognizing the dearth of SME crisis management studies in the existing literature of crisis management, this systematic literature review on SMEs aims to recognize the issues around academic research on SME crisis management and to identify the strategies applied by small business entrepreneurs against crisis vulnerability. Thus, two questions are addressed: what has been done in SME crisis management research, and what trends have marked this phenomenon in research arenas. This review considered 181 research articles published on SME crisis management since 2000. Exploring the existing SME crisis management literature identified three major themes: Crisis preparedness measures, Crisis impact on SMEs, and SMEs' strategic approach. Following the identification of gaps in the literature, the findings suggest future research areas of SME crisis management with organizational perspective, crisis experience towards crisis learning, crisis learning as a strategic approach, and networking as a social coping strategy. The synthesis action also directed future research in the field.
\end{abstract}

Keywords: Small and Medium Scale Enterprises (SMEs); Organizational crisis; Crisis Management; Crisis Learning; Crisis Preparedness; Systematic Review 


\section{Introduction}

Organizational management has received significant attention in the academic research literature, whereas organizational crisis management has received comparatively less attention. (Simola, 2005). Organizational Crisis refers to "lowprobability, high-impact event that threatens the viability of the organization and is characterized by ambiguity of cause, effect, and means of resolution, as well as by a belief that decisions must be made swiftly" (Pearson \& Clair, 1998). Those are considered significant, unpredictable circumstances that an organization may face during their regular business operations. The direct and indirect effects of different types of crises can impact the business entities, and the vulnerability depends on mitigating the adverse effects of crisis.

Uncertainty in the business environment leads to crises within organizations. Despite the type of crisis, businesses need to manage such contingencies to survive in the long run. Crisis management is defined as "the discipline of preparing the resources and organizational structures necessary to respond effectively in the face of a crisis and recover effectively in the aftermath" (Vargo \& Seville, 2011). The three main phases in crisis management are the pre-crisis, crisis, and post-crisis phases (Coombs \& Laufer, 2018; Smith, 1990). Accordingly, the pre-crisis phase considers prevention and preparation for the crisis to minimize the adverse effects. The post-crisis phase considers response and recovery from the crisis. Hence the essential elements in crisis management consist of mitigation/prevention, preparedness, response and recovery/revision (Hilliard, Scott-Halsell, \& Palakurthi, 2011).

In the organizational context, the crisis management literature emphasized the more vulnerability of SMEs for crises compared to larger organizations (Herbane, 2006, 2010a; Kato \& Charoenrat, 2017). Although there is no commonly accepted definition for SMEs, the number of employees and/or annual turnover are commonly used to identify SMEs. Accordingly, the National Policy Framework (2016) defines SMEs as firms with fewer than 300 employees (manufacturing sector) or 200 employees (service sector) and an annual turnover of less than LKR 750 million. Being SMEs representing more than $90 \%$ of total businesses, the contribution toward the national production and empowerment of employees is significant (Khalique, Isa, \& Shaari, 2011; Kato \& Charoenrat, 2017; Sardana \& Dasanayaka, 2013). Thus, SMEs are considered the backbone of any economy due to their significant contribution (Romme, 1997). These consequences emphasise the importance of SME crisis management studies in the organizational context. 
The existing SME crisis management literature spread over all three phases of the crisis; pre, trans and post-crisis phases. Former studies were mainly highlighted the generic characteristics (Herbane, 2010; Orchiston, 2013) and personal traits of ownermanagers (Josephson, Schrank, \& Marshall, 2017; Pathak \& Ene, 2017) of SMEs to determine the vulnerability of SME crisis. However, the recent literature has emphasized the importance of more strategic approaches (Doern, Williams, \& Vorley, 2019; Herbane, 2019; Mayr, Mitter, \& Aichmayr, 2017) and enhancing the resource base to be resilient in a crisis (Branicki, Sullivan-Taylor, \& Livschitz, 2018; Herbane, 2019; Mayr et al., 2017). While it identifies the reactive nature of SMEs for the crisis due to the limited focus on cash flow led by the limitation of resourcefulness (Doern, 2014; Herbane, 2010a), more recent studies highlight the necessity of strategic orientation (Kottika et al., 2020; Crick, Eskander, Fankhauser, \& Diop, 2018; Doern, Williams, \& Vorley, 2019; Herbane, 2019). Although the crisis management literature emphasized the evolutionary trend of organizations as identifying crises from reactive to proactive approach (Shrivastava, 1993), it is doubtful to consider such an evolution with SMEs due to various inherent limitations.

Hence the inconsistency of findings in former empirical studies identified the requirement of synthesization of SME crisis management. This study aims to broaden knowledge by learning key research areas, understanding the prevailing knowledge, identifying existing gaps, and directing future research areas in SME crisis management studies. Notably, a thorough examination of recent literature may allow comprehending the current state of knowledge in the area. It is critical to know the key research areas of SMEs crisis management in SME crisis management literature while understanding the limitations of these studies. It may lead to finding the gaps in existing literature while reflecting the future research areas.

\section{Methodology}

This study reviews the pertinent literature on previous theoretical and empirical studies on SME crisis management. A systematic literature review has been deployed to ensure the procedural accuracy of the process.

Major online databases were considered to select key articles using relevant terms. Since this study focused on recent literature, the articles were limited to those published between 2000 and 2020. Related articles were downloaded using the search themes "SME" and "Crisis Management." In order to avoid missing relevant articles, the search terms were kept broad. For example, from "Science Direct", the received 
outcome is 140 articles. The same procedure was followed with other online databases such as Emerald, Wiley online library, Tailor and Francis and SAGE online, and the outcome produced 482 articles. After reviewing all of the results and removing duplicate documents, 181 articles remained.

It referred to the abstracts of all selected articles to identify the relevance to the topic and selected 41 relevant articles for further consideration. The author referred to the full papers to understand the research findings of each of the articles. Thus, it has selected 26 high impact articles for the final analysis. The number of citations of such articles was mainly considered for selecting them as articles with high impact. Since the year of publication matters for the number of citations, the journal rank was considered against the recent articles selected for final consideration. Subsequently, the data were synthesized.

The data was limited to the journal articles considering the major contribution and the validity and reliability of the information. An advanced search technique of time limitation was used as "2000 to 2020 ". Even within this time duration, it has eliminated other articles such as review articles, book chapters, and conference articles.

The key research areas were identified by referring to each article. The identification of research themes is intended to group the articles under each theme. Independently classified articles under each theme were further classified under developed subthemes. This categorization leads to easy reference of major research areas, key authors and immerging trends in the field. Finally, the analysis is directed to identify the gaps in the existing literature and direct new research areas to be studied in the future.

\section{Derivation of Themes}

The thematic analysis refers to 26 relevant and high impact articles in SME crisis management literature. Three major themes were derived from the process as Crisis Preparedness Measures, Crisis Impact on SMEs and Strategic Approach of SMEs for Resilience. Comprehensive analysis of the selected articles under each of those themes was directed to identify the following sub themes relevant major research areas in figure 1 .

Journal of Business Studies, 7(2)

$-22-$

2020 


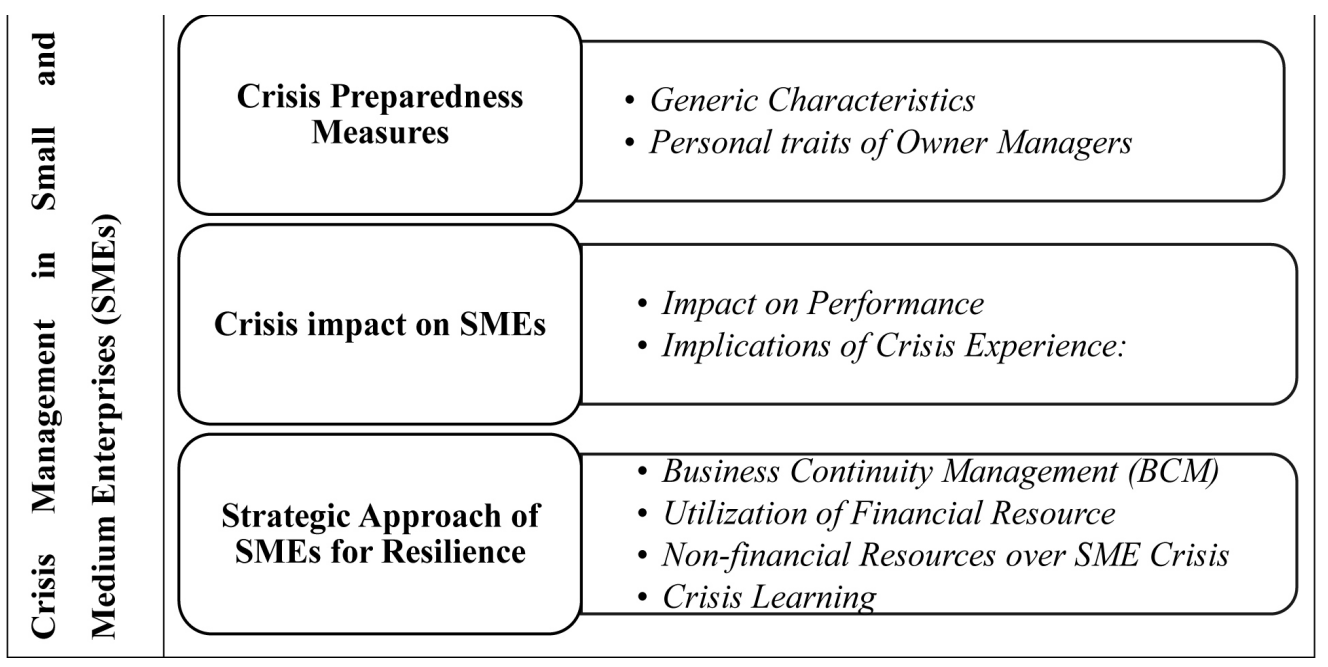

Figure 1: Thematic Analysis

The authors identified the main research area by referring to selected full papers. The articles were then categorized based on the common characteristics encountered. Overall, the data synthesis in those research articles resulted in the identification of three major themes and eight sub-themes, as follows in table no 1: 
Table 1: Themes Developed and Relevant Articles

\begin{tabular}{|c|c|}
\hline \multicolumn{2}{|c|}{ Crisis Preparedness Measures } \\
\hline \multirow[t]{3}{*}{ - Generic Characteristics: } & $\begin{array}{l}\text { Resource limitation results in SMEs' proactive nature } \\
\text { for the crisis. } \\
\text { (Auzzir, Haigh, \& Amaratunga, 2018; Herbane, 2010; } \\
\text { Doern, 2014) }\end{array}$ \\
\hline & $\begin{array}{l}\text { Impact of SMEs' size and age on crisis preparedness. } \\
\text { (Orchiston, 2013;Simón, Revuelto, \& Ribeiro, 2016) }\end{array}$ \\
\hline & $\begin{array}{l}\text { Crisis preparedness concern is affected by the past crisis } \\
\text { experience rather than the existence of the crisis } \\
\text { management team.(Spillan \& Hough, 2003) }\end{array}$ \\
\hline \multirow[t]{4}{*}{$\begin{array}{l}\text { - Personal traits of } \\
\text { Owner-Managers: }\end{array}$} & $\begin{array}{l}\text { Gender and level of education on crisis management } \\
\text { impact.(Josephson, Schrank, \& Marshall, 2017; Pathak } \\
\text { \& Ene, 2017) }\end{array}$ \\
\hline & $\begin{array}{l}\text { Crisis resilience concerns of owner-managers. } \\
\text { (Tibay et al., 2018) }\end{array}$ \\
\hline & $\begin{array}{l}\text { The psychological impact of SME owner-managers and } \\
\text { possible strategies identified. (Doern, 2014) }\end{array}$ \\
\hline & $\begin{array}{l}\text { Impact of a crisis experience. } \\
\text { (Herbane, 2006; Spillan \& Hough, 2003) }\end{array}$ \\
\hline \multicolumn{2}{|l|}{ Crisis impact on SMEs } \\
\hline \multirow[t]{3}{*}{ Impact on performance: } & $\begin{array}{l}\text { Factors that affect SME crisis recovery. } \\
\text { (Asgary, Imtiaz, \& Azimi, 2012) }\end{array}$ \\
\hline & $\begin{array}{l}\text { Short term and long-term effects of a crisis on SMEs. } \\
\text { (Samantha, 2018; Auzzir et al., 2018) }\end{array}$ \\
\hline & $\begin{array}{l}\text { The direct and indirect effect of a crisis for SMEs. } \\
\text { (Irvine \& Anderson, 2003) }\end{array}$ \\
\hline
\end{tabular}

Journal of Business Studies, 7(2)

$-24-$

2020 


\begin{tabular}{|c|c|}
\hline \multirow[t]{4}{*}{$\begin{array}{l}\text { Implications of crisis } \\
\text { experience: }\end{array}$} & $\begin{array}{l}\text { Crisis experience determines crisis preparedness. } \\
\text { (Josephson et al., 2017) }\end{array}$ \\
\hline & $\begin{array}{l}\text { Crisis experience to create crisis concern. } \\
\text { (Spillan \& Hough, 2003) }\end{array}$ \\
\hline & $\begin{array}{l}\text { Lack of crisis experience may increase vulnerability. } \\
\text { (Auzzir et al., 2018; Doern, 2014) }\end{array}$ \\
\hline & $\begin{array}{l}\text { Inability to correlate crisis experience with crisis } \\
\text { preparedness.(Herbane, 2006; Kato \& Charoenrat, 2017) }\end{array}$ \\
\hline \multicolumn{2}{|c|}{ Strategic Approach of SMEs for Resilience } \\
\hline $\begin{array}{l}\text { Business Continuity } \\
\text { Management (BCM): }\end{array}$ & $\begin{array}{l}\text { The strategic planning process for disaster risk reduction } \\
\text { (Herbane, 2006, 2010b; Kato \& Charoenrat, 2017) }\end{array}$ \\
\hline \multirow[t]{3}{*}{$\begin{array}{l}\text { Utilization of Financial } \\
\text { Resource: }\end{array}$} & $\begin{array}{l}\text { Strategies for financial crisis management. } \\
\text { (Kottika et al., 2020) }\end{array}$ \\
\hline & $\begin{array}{l}\text { External sources at the financial crisis phase. } \\
\text { (Carbó-Valverde, Rodríguez-Fernández, \& Udell, 2016) }\end{array}$ \\
\hline & $\begin{array}{l}\text { Risk adaptation contributors. } \\
\text { (Crick et al., 2018) }\end{array}$ \\
\hline \multirow[t]{3}{*}{$\begin{array}{l}\text { Non-financial resources } \\
\text { over SME crisis: }\end{array}$} & $\begin{array}{l}\text { Factors which affect strategic approaches. } \\
\text { (Mayr et al., 2017) }\end{array}$ \\
\hline & $\begin{array}{l}\text { SME characteristics over strategic orientation. } \\
\text { (Doern et al., 2019; Herbane, 2019; Mayr et al., 2017) }\end{array}$ \\
\hline & $\begin{array}{l}\text { Networking to enhance the resource base. } \\
\text { (Battisti \& Deakins, 2015; Branicki et al., 2018; } \\
\text { Herbane, 2019; Mayr et al., 2017) }\end{array}$ \\
\hline \multirow[t]{2}{*}{ Crisis Learning: } & $\begin{array}{l}\text { Organizational learning towards SME crisis learning. } \\
\text { (Herbane, 2014, 2019; Saunders, Gray, \& Goregaokar, } \\
\text { 2014) }\end{array}$ \\
\hline & $\begin{array}{l}\text { Learning as a tool to expand the resource base. } \\
\text { (Allan, Herbane, \& Jones, 2015; Mayr et al., 2017) }\end{array}$ \\
\hline
\end{tabular}




\subsection{Crisis Preparedness Measures}

The characteristics of SME crisis preparedness can be identified in two main aspects, namely generic characteristics and the personal traits of SME owner-managers. Accordingly, generic characteristics refer to the organizational specific features. The human-specific charisma can be discussed under the personal traits of ownermanagers of SMEs.

\subsubsection{Generic characteristics}

The characteristics of SME crisis preparedness was measured using different criteria. The majority of studies considered the general characteristics of SMEs, such as business size, age of the business and capacity of available resources.

Limited resources of SMEs are vital and highlighted in former empirical studies. Among them, financial constraints are significant (Pathak \& Ene, 2017; Auzzir, Haigh, \& Amaratunga, 2018; AlBattat \& MatSom, 2014), and the limited focus on cash flow (Herbane, 2010) result in restricting the access to advise and support (Doern, 2014) that causes to increase the vulnerability for the crisis.

Orchiston (2013) identified the age of an SME as a vital factor in undertaking resilience tools, apart from the business size. Former empirical studies stressed that the preparedness of SMEs depends on situational factors, namely size of the business, prior experience and property ownership (Josephson et al., 2017). According to the author, new SME tourism operators, compared to established firms, were unaware of the impact of a disaster despite being aware of potential disasters. On the contrary, Simón et al. (2016) stressed that new firms have a higher potential to survive the crisis than matured firms.

The existence of crisis plans and the formation of a crisis management team received due recognition in SME crisis management studies to evaluate their crisis preparedness. Spillan \& Hough (2003) found no significant difference in crisis preparedness between SMEs who possess the crisis management team and the SMEs who possess such a crisis management team.

\subsubsection{Personal traits of owner-managers:}

This topic focuses on the characteristics of SME owner-managers towards crisis management priorities. Among these, the owner's characteristics, such as gender and 
education (Josephson et al., 2017), have been identified as having a significant impact on crisis management. Gendered impact on crisis preparation found that the social expectations and the gender-specific roles as crucial reflectors of their behaviour within enterprises. Higher assistance towards SMEs and higher learning capacities of female entrepreneurs were identified as the strengths (Pathak \& Ene, 2017; Josephson et al., 2017). Similarly, weaknesses such as lack of innovations, higher mental trauma, and inaccurate risk perception were identified (Pathak \& Ene, 2017).

However, certain studies have prioritised the effect of owners or the top managers of SMEs perception for studying crisis preparedness. Among the key resilience factors of SMEs, leadership and management, the core competence of staff, market sensitivity, situational awareness and preparedness plans were primary attributes of considering SME resilience of crisis (Tibay et al., 2018).

The psychological impact on SME owner-managers evaluated the vulnerability and resilience of owner-managers. They identified the possible strategies, namely social coping strategy, through physical support, emotional support, financial support, and information through the community and other business partners (Doern, 2014).

Perceptional importance on the crisis of owner-managers was studied concerning crisis preparedness and found that it is mainly influenced by the experience of ownermanagers (Spillan \& Hough, 2003). Herbane (2006) stated that SMEs do not clearly understand the long-term effects of the crisis. While the study revealed no significant difference between planning and non-planning SMEs on the ranking of the ability to plan for specific crisis types, the post-crisis impact was found to differ between planning and non-planning SMEs. However, the managers' experience of the crisis was not directly reflected in their planning priorities. Irvine \& Anderson (2003) convinced that firms who planned appeared to faced the crisis better and emphasized the vital role of communication on the customer perception at a crisis phase.

\subsection{Crisis impact on SMEs}

Former empirical studies identified more vulnerability of SMEs for crisis compared to larger organizations. The impact of crisis may directly affect the physical resources of SMEs, influencing the overall performance. Parallelly, the crisis experience may influence the personal traits of owner-managers. 


\subsubsection{Impact on performance}

The effects of natural disasters were widely discussed in SME crisis management and found that the effect is significant for SMEs survival. According to Asgary, Imtiaz, \& Azimi (2012), 90\% of SMEs operate with a loss after hitting a disaster. Even after six months, majority of them were running slower than the pre-crisis level operations. The authors further stated that the crisis recovery period of a SME is affected by average monthly sales, former crisis experience, and dependency on infrastructure facilities, personal savings, damages on properties and lives and involvement with stakeholders.

The short term and long term impact of natural disasters on SMEs lead to the identification of four significant vulnerability fronts: capital, labour, logistics and markets (Samantha, 2018). Similarly, Auzzir, Haigh, \& Amaratunga (2018) stated that the loss of sales, nonattendance of employees and damage to property are the most critical impacts of SME crisis. Furthermore, the authors emphasised the financial implications of such effects and the impact of insufficient support from the expertise and relevant information.

The effect of the pandemic situation has affected SMEs of specific industries. The tourism industry was highly impacted due to the foot and mouth disease and cause to loss of trade as the tourist arrivals were reduced (Irvine \& Anderson, 2003). The indirect effects were experienced as a loss of supply, product offering change, and limitations for future investments. The findings disclosed a significant effect of endemic on the tourism industry regarding the volume of business, profitability and reductions of staff numbers.

\subsubsection{Implications of crisis experience}

Former crisis experience was identified as the foremost determinant of the vulnerability of SMEs in all three phases of the crisis. Josephson et al. (2017) explained that prior disaster experience or prior experience with adversity seems to be an important factor in determining SMEs' level of crisis preparedness. Spillan \& Hough (2003) revealed that former crisis experiences are vital for SMEs to be crisis concerned. The lack of prior experience in crises negatively impacted the vulnerability of SMEs (Auzzir et al., 2018; Doern, 2014). A study conducted to understand how the experiences of owner-managers affect the response phase concluded with the findings; experience, mindset and resources as key considerations of small 
businesses' resilience or vulnerability for a crisis. The findings further indicated the importance of protecting valuable resources for a better response to crises for small businesses (Doern, 2014). In contrast, Kato \& Charoenrat (2017) emphasised that there is no significant impact from prior crises experience on crisis preparedness of SMEs as more experience on crisis does not result in higher level of crisis preparedness. The crisis experience of owner managers were not directly reflect in the planning and non-planning priorities of SMEs (Herbane, 2006).

\subsection{Strategic Approach of SMEs for Resilience}

The strategic approach and the ability of owner-managers to think and work strategically decide the long-term survival of SMEs (Vargo \& Seville, 2011). A study conducted to assess the relationship between management concern for organizational crises and competitive strategy discovered that SMEs in developing countries had lower strategic orientation than SMEs in developed countries (Parnell, 2009). However, the limited capabilities in resourcefulness and technical systems cause the strategic approach of SMEs to differ from larger organizations, but rapidity strength is higher than larger organizations (Sullivan-Taylor \& Branicki, 2011).

\subsubsection{Business continuity management (BCM)}

$\mathrm{BCM}$ and crisis management were incorporated in crisis management studies mainly concerning crisis preparedness. The majority of these studies highlighted business continuity planning as a part of strategic planning. Similarly, it is the widely used term with organizational planning and resourcing for crisis prevention and crisis management (Herbane, 2010a). Accordingly, it is not merely disaster recovery planning but considers a wide range of planning, including anticipating failures, planning and rehearse to protect the business and deliver stakeholders' interests (Herbane, 2019). As a part of strategic planning, crisis planning explores possibilities for businesses to be more resilient and find opportunities (Vargo \& Seville, 2011; Herbane, 2019).

Beyond the view of crisis management as an intuition-driven process, crisis management plays an important role in the strategic management process of an organization (Herbane, 2006). Kato \& Charoenrat (2017) incorporated BCM with strategic crisis planning for Disaster Risk Reduction (DRR). The study further revealed that the DRR practices of perceived disaster readiness, business continuity knowledge and training needs are positively correlated with a scale of business size, operation period and disaster experience of SMEs. 


\subsubsection{Resource utilization}

SME resource management ranges from managing in-house resources to expanding the resource base through external sources. SMEs must manage both their financial and non-financial resources within their internal resources. The strategic implementation may widen the resource base of SMEs, resulting in higher performance (Premaratne, 2001).

Financial Resources: Being one of the limited primary resources that affect SMEs' survival, financial resource management against crisis resilient received considerable attention in crisis management literature. Thus, the financial crisis may cause the overall operation of SMEs. Similarly, the financial crisis management and the strategic approach for financial crisis management is vital in the overall crisis management strategy of the SME. Therefore, Kottika et al. (2020) revealed that environmental analysis, operation coordination, development of productivity and efficiency, financial and marketing activities, downsizing and partnership development are vital in the strategic approach of SME survival in a financial crisis. Alternative sources of external financial facilities for SME's varied across trade credit to bank loans. While credit-constrained institutions mainly depend on trade credits, unconstrained SMEs heavily depend on bank loans (Carbó-Valverde et al., 2016). This indicates that trade credit is crucial during times of crisis. While the limitation of financial resources is a factor that negatively affects risk adaptation, business support and assistance services and access to information technology are considered as factors that may positively contribute to SMEs adoption (Crick et al., 2018).

Non-financial Resources: The non-financial resources management against crisis management of SMEs was mainly discussed in former empirical studies on internal strategy development and expanding the resource base through networking with stakeholders. Even the variations on the strategic resilience approach of SMEs were identified according to SME characteristics.

Herbane (2019) studied the resilient management orientation as a strategic management approach of SMEs to identify whether there is any difference due to the existence or absence of strategic and resilience management strategies according to the location, external crisis events, personal networks, and attitudes. Besides, a significant difference has been identified according to clusters in terms of business size, age, and business activity. Doern, Williams, \& Vorley (2019) emphasized, 
whether and how entrepreneurs respond to a crisis may depend on several factors. These include experience, stage of business development, the type or stage of the crisis affecting the business, and resources, both in terms of how resources are used and the suitability for the crisis stage. In comparison, while stating that the age of SMEs has a minor and adverse effect on strategic crisis response, the use of nonfinancial variables for strategic repositioning of SMEs during the crisis response phase identified the influential factors. Such factors consist of a unique selling proposition combined with innovation and change and integration into networks (Mayr et al., 2017).

Branicki, Sullivan-Taylor, \& Livschitz (2018) have criticized the entrepreneurial resilience of SMEs with reference to the traditional view of resource limitation. Instead, they suggested the possible intervention of the government or SME networks. The organizational resilience and strategic renewal of SMEs depend on the cooperation of entrepreneurial activities and planning, networks, learning, and location. Battisti \& Deakins (2015)have applied dynamic capability to understand the organizations' capability to integrate external resources through the network with external organizations. So that integrating external resources may strengthen the firm's resource base and enable it to respond effectively in a highly volatile environment.

\subsubsection{Crisis learning}

Being resilient from the crisis is vital for SMEs to ensure survival in the long run. Knowledge creation through crisis learning is important for SMEs to cope with resource limitations while being resilient to the crisis. Although crisis management literature highlighted the reactive nature of SMEs (Herbane, 2010a), crisis learning is essential to minimize the vulnerability of SMEs. Beyond the learning on business potentials, organizational learning may lead to risk identification for entrepreneurs. Individuals, such as owner-managers and/or other chief managers in SMEs implement a significant role within the learning process due to the inherent characteristics of SMEs as they are the key decision-makers in the business. Although individual and group learning is vital in young organizations, the embedded prior learning within the organization is predominant when organizations mature (Crossan, Lane, White, \& White, 2008). 
Furthermore, Herbane (2019) stated that learning across organizations potentially enhances resilience. The crisis learning capacity of SMEs may be created through the accumulation of knowledge, skills, and assets. Those may even result in minimizing the resource limitation (Allan et al., 2015). Saunders, Gray, \& Goregaokar (2014) highlighted the importance of the role of SME leaders to encourage learning as a part of their shared organizational vision. It was discovered that newly established SMEs are more learning-oriented and are interested in both formal and informal sources of learning.

Herbane (2014) studied how organizational learning can direct crisis learning and the perceived usefulness of information for crisis preparation. The author described crisis preparedness as an isomorphic learning and a knowledge transferring process, where information is vital. As risk perception of managers is influenced by the degree of trust placed in the source of information and such information as a precursor for organizational learning, the study focuses on understanding how SMEs may perceive information for crisis learning. A more recent study by Herbane (2019) stressed that personal crisis experience might enhance the knowledge on the crisis through crisis learning while the awareness of the crisis with other organizations may direct to isomorphic learning. Resource-Based View (RBV) can also study how organizations can learn from failure and innovate, adapt and renew the resources to provide a competitive advantage (Mayr et al., 2017).

\section{Discussion}

Central to the objective of this study to understand the existing knowledge in the SME crisis management literature, it analyzed the recent SME crisis management literature and was able to identify the trends, gaps, and limitations of current literature, to guide future studies (refer to table 2).

Journal of Business Studies, 7(2)

$-32-$

2020 
Table 2: Gaps in the SME Crisis Management Literature

\begin{tabular}{|c|c|}
\hline Existi & Areas with less research \\
\hline $\begin{array}{l}\text { - Crises were identified as a threat. } \\
\text { - Identify the associated risk/ crisis } \\
\text { impact on SMEs. } \\
\text { - Highlighted the reactive behaviour } \\
\text { of SMEs. } \\
\text { - Indicated the cognitive learning } \\
\text { approaches. } \\
\text { - More quantitative studies. } \\
\text { - More studies were conducted based on } \\
\text { developing economies. } \\
\text { - All industries were considered. } \\
\text { - Mainly the data were collected through } \\
\text { self-reported information. }\end{array}$ & $\begin{array}{l}\text { - Crisis as an opportunity. } \\
\text { - Strategic approach for SME crisis } \\
\text { management. } \\
\text { - Strategic management approaches } \\
\text { that could expand the resource base. } \\
\text { - Participatory learning approaches. } \\
\text { - Comparatively less qualitative studies. } \\
\text { - Lesser studies were based on } \\
\text { developed nations. } \\
\text { - Industry-specific studies were limited. } \\
\text { - Data reporting through a third party. }\end{array}$ \\
\hline
\end{tabular}

To examine crisis preparedness, vulnerability, and resilience, SME crisis management studies were expanded over all three phases of crisis: pre-crisis, crisis, and post-crisis phases. In most cases, it is noticeable that it was unable to identify crisis as an opportunity but as a threat (Wang, 2008).

Although there are many studies on the types of crisis, the impact on the crisis, and related studies, the strategic approach for crisis management in SMEs was less explored in depth. Such explorations on quantifiable factors may comparatively possess more quantitative studies in SME crisis management literature. Much of the former studies discussed the strategic planning approaches, which concentrate mainly on risk identification and crisis preparedness concerns but not strategic crisis management, where it parallelly finds development opportunities.

Much of the SME crisis management has highlighted the lack of resources of SMEs, which leads to reactive behaviour against the crisis. Rather than considering the lack 
of resources of SMEs as a limitation, more empirical studies may need to explore the available opportunities due to such characteristics of SMEs. Exceptionally, strategic approaches could be adopted to address resource limitations. The benefits of synergy could be a potential approach, and certain studies highlighted the potential strategies, namely networking, experience sharing, creating a shared vision, and assistance through stakeholders. However, most of those studies were discussed inadequately and superficially.

Crisis learning as a strategic resilience approach for crisis management could be considered and explored in-depth. It could cope with the existing resource base as it mainly constitutes human factors within the organization. However, the learning orientation of SMEs in crisis management was comparatively less studied towards identification on organizational learning approach for crisis management. Even though SMEs' dynamic capability and resource integration were discussed in the crisis management of SMEs, less consideration was given to the learning.

Organizational learning may lead to creating knowledge on effective crisis management and, such knowledge may cause to implement best practices (Elliott \& Macpherson, 2010) within the SMEs to respond effectively to crises. Learning can be incorporated at each stage of the crisis, and specifically, organizational learning is more applicable for pre, trans, and post phases in crisis management (Herbane, 2014; Smith, 1990; Wang, 2008). Therefore, applying organizational learning in crisis learning may improve the knowledge of employees across different levels of the organization, which may result in effective crisis response for a crisis within an organization.

The literature indicates a significant gap between the crisis experience of SMEs and learning through crisis experience. It has often discussed the two areas separately but not comprehensively evaluated the relationship and/or the interdependency of those with SME crisis management. According to Elliott \& Macpherson (2010), lessons learned from previous crisis event(s) can be meaningful when effectively practising and applying in new situations. Nevertheless, the experiences accumulated by an organization are the basis for organizational learning (Argote, 2011) which could even apply to SME crisis management. Being crisis learning directed to isomorphic learning and vicarious learning through the experience of stakeholders, it is required to explore the participatory learning approaches of SMEs through SME crisis learning. 
Furthermore, the existing SME crisis management literature highlighted that the majority of the studies focused on developed economies compared to developing economies. Notably, the qualitative studies conducted for in-depth analysis were limited to developing countries. More qualitative data may provide self-reported information through surveys (Hobfoll, 1989), which was commonly used in previous studies. Instead, it will use the method of third-party data collection, result in reducing the bias information.

Given the contribution of the identification of themes through the systematic review, the following gaps can be derived in the SME crisis management empirical research in figure 2 .

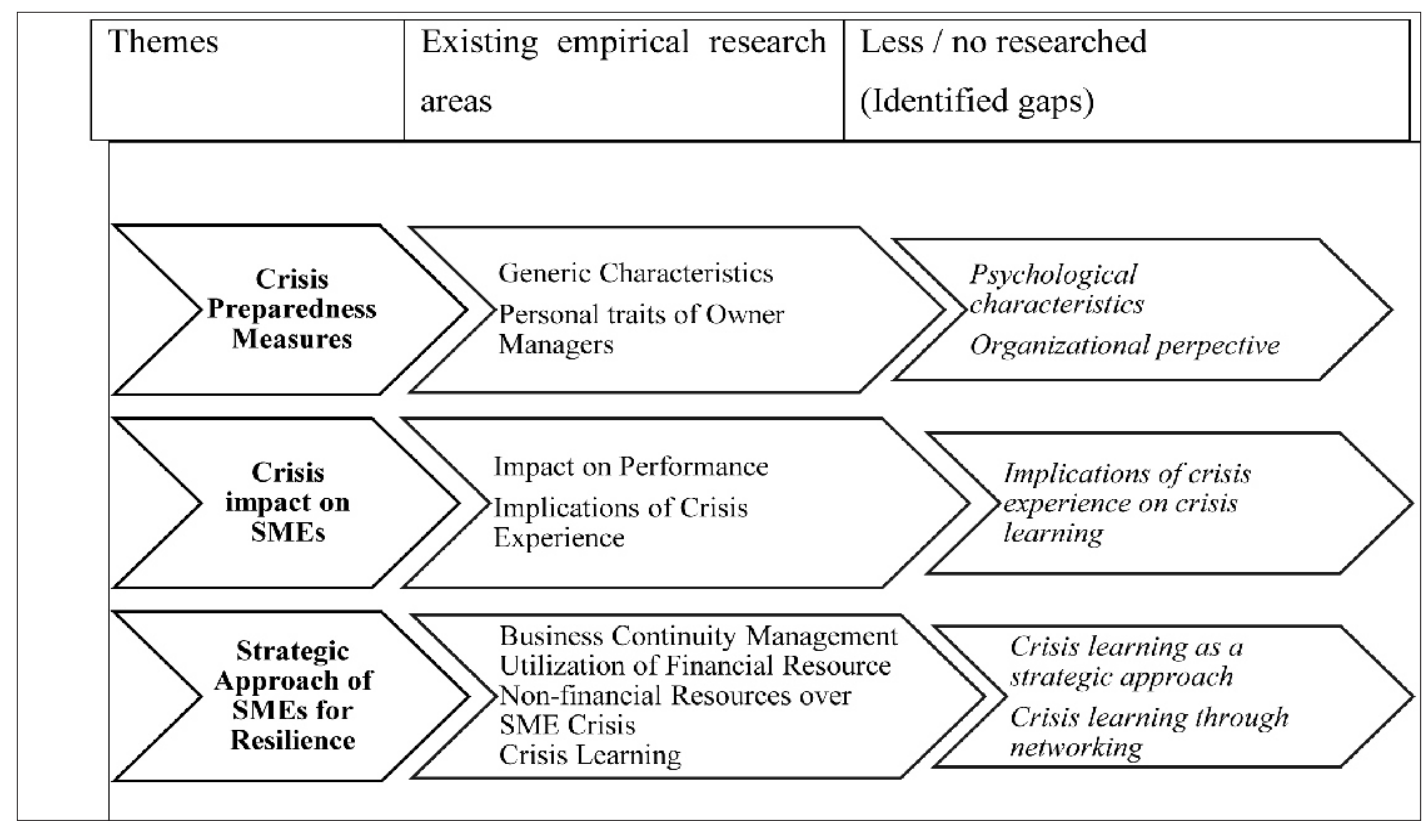

\section{Figure 2: Identification of Future Research Trends through Thematic Analysis}

Having explored the existing empirical studies in the SME crisis management arena, less or minimum exploration areas were identified in several aspects. Rather than being limited to owner-centered activities, the organizational perspective is applied to all aspects, including crisis management orientation in SMEs. Indeed, the embedded knowledge within the organization and the experiential learning orientation of SMEs have received less attention. Although it has identified crisis learning as a strategic approach to being resilient with SME crises, it has not incorporated experiential 
learning. Social coping strategies were mainly concentrated on the expansion of the physical resource base. However, the crisis learning of SMEs has not explored the organizational experiential approach through social networking. This identification of the nonexistence of interrelationship with each of these identified gaps in the literature may lead to studying SMEs' organizational experiential learning behaviour towards SME strategic orientation for crisis management. Future research could be conducted separately in each phase of the crisis or linked together from an organizational perspective.

\section{Conclusion}

This systematic literature review leads to analyse the existing empirical research in the SME crisis management literature. Compiling the research findings of former studies and data synthesis resulted in the derivation of major themes in SME crisis management literature as crisis preparedness measures, crisis impact on SMEs, and SMEs' strategic approach.

Further exploration research findings through the identified themes depicted the gap in the literature indicating the future research requirements with more organizational perspective, crisis experience towards crisis learning, crisis learning as a strategic approach and networking as a social coping strategy.

However, the systematic literature review is limited to data extracted from major online databases. As a result, small group research findings and findings published in languages other than English are not included. Furthermore, the findings of parallel studies could not be considered in this review. As a result, future reviews may need to address the limitations and broaden the scope of the review.

Journal of Business Studies, 7(2)

$-36-$

2020 


\section{References:}

AlBattat, A. R., \& MatSom, A. P. (2014). Emergency Planning and Disaster Recovery in Malaysian Hospitality Industry. Procedia - Social and Behavioral Sciences, 144, 45-53. https://doi.org/10.1016/j.sbspro.2014.07.272

Allan, Herbane, B., \& Jones, O. (2015). Developing dynamic capabilities through resource accretion? expanding the entrepreneurial solution space. 5626(September). https://doi.org/10.1080/08985626.2015.1038598

Argote, L. (2011). Management Learning research? Past, present and future. https://doi.org/10.1177/1350507611408217

Asgary, A., Imtiaz, M., \& Azimi, N. (2012). Disaster recovery and business continuity after the 2010 flood in Pakistan? Case of small businesses. International Journal of Disaster Risk Reduction, 2, 46-56. https://doi.org/10.1016/j.ijdrr.2012.08.001

Auzzir, Z., Haigh, R., \& Amaratunga, D. (2018). Impacts of Disaster to SMEs in Malaysia. Procedia Engineering, 212, 1131-1138. https://doi.org/10.1016/ j.proeng.2018.01.146

Battisti, M., \& Deakins, D. (2015). The relationship between dynamic capabilities, the firm's resource base and performance in a post-disaster environment. (December 2011). https://doi.org/10.1177/0266242615611471

Branicki, L. J., Sullivan-Taylor, B., \& Livschitz, S. R. (2018). How entrepreneurial resilience generates resilient SMEs. 24(7).

Carbó-Valverde, S., Rodríguez-Fernández, F., \& Udell, G. F. (2016). Trade Credit, the Financial Crisis, and SME Access to Finance. Journal of Money, Credit and Banking, 48(1), 113-143. https://doi.org/10.1111/jmcb.12292

Coombs, W. T., \& Laufer, D. (2018). Global Crisis Management - Current Research and Future Directions. Journal of International Management, 24(3), 199-203. https://doi.org/10.1016/j.intman.2017.12.003

Crick, F., Eskander, S. M. S. U., Fankhauser, S., \& Diop, M. (2018). How do African SMEs respond to climate risks? Evidence from Kenya and Senegal. World Development, 108, 157-168. https://doi.org/10.1016/j.worlddev.2018.03.015 
Crossan, M. M., Lane, H. W., White, R. E., \& White, E. (2008). Learning from intuition to framework? 24(3), 522-537.

Doern, R. (2014). Entrepreneurship and crisis management? The experiences of small businesses during the London 2011 riots. https://doi.org/10.1177/ 0266242614553863

Doern, R., Williams, N., \& Vorley, T. (2019). Special issue on entrepreneurship and crises? business as usual? An introduction and review of the literature. Entrepreneurship \& Regional Development, 31(5-6), 400-412. https://doi.org/ $10.1080 / 08985626.2018 .1541590$

Elliott, D., \& Macpherson, A. (2010). Policy and practice: Recursive learning from crisis. Group and Organization Management, 35(5), 572-605. https://doi.org/ $10.1177 / 1059601110383406$

Herbane, B. (2006). Exploring Crisis Management in UK Small- and Medium-Sized. 2(2).

Herbane, B. (2010a). Small business research: Time for a crisis-based view. International Small Business Journal, 28(1), 43-64. https://doi.org/ $10.1177 / 0266242609350804$

Herbane, B. (2010b). The evolution of business continuity management: A historical review of practices and drivers. Business History, 52(6), 978-1002. https://doi.org/10.1080/00076791.2010.511185

Herbane, B. (2014). Information Value Distance and Crisis Management Planning. https://doi.org/10.1177/2158244014532929

Herbane, B. (2019). Rethinking organizational resilience and strategic renewal in SMEs. Entrepreneurship \& Regional Development, 31(5-6), 476-495. https://doi.org/10.1080/08985626.2018.1541594

Hilliard, T., Scott-Halsell, S., \& Palakurthi, R. (2011). Elements that influence the implementation of crisis preparedness measures by meeting planners. Journal of Contingencies and Crisis Management, 19(4), 198-206. https://doi.org/ 10.1111/j.1468-5973.2011.00644.x

Journal of Business Studies, 7(2)

$-38-$

2020 
Irvine, W., \& Anderson, A. R. (2003). The impacts of foot and mouth disease on a peripheral tourism area: The role and effect of crisis management. Tourism Crises: Management Responses and Theoretical Insight, 47-60. https://doi.org/10.1300/J073v19n02_05

Josephson, A., Schrank, H., \& Marshall, M. (2017). Assessing preparedness of small businesses for hurricane disasters: Analysis of pre-disaster owner, business and location characteristics. International Journal of Disaster Risk Reduction. https://doi.org/10.1016/j.ijdrr.2017.03.013

Kato, M., \& Charoenrat, T. (2017). Business Continuity Management of Small and Medium Sized Enterprises: Evidence from Thailand. International Journal of Disaster Risk Reduction. https://doi.org/10.1016/j.ijdrr.2017.10.002

Khalique, M., Isa, A. H. M., \& Shaari, J. A. N. (2011). Challenges for Pakistani SMEs in a Knowledge-Based Economy Muhammad Khalique 1, Abu Hassan Md. Isa 2 and Jamal Abdul Nassir Shaari 3. 5(2), 74-80.

Kottika, E., Özsomer, A., Rydén, P., Theodorakis, I. G., Kaminakis, K., Kottikas, K. G., \& Stathakopoulos, V. (2020). We survived this! What managers could learn from SMEs who successfully navigated the Greek economic crisis. Industrial Marketing Management, 88(May), 352-365. https://doi.org/10.1016/ j.indmarman.2020.05.021

Mayr, S., Mitter, C., \& Aichmayr, A. (2017). Corporate Crisis and Sustainable Reorganization: Evidence from Bankrupt Austrian SMEs. Journal of Small Business Management, 55(1), 108-127.https://doi.org/10.1111/jsbm.12248

Orchiston, C. (2013). Tourism business preparedness, resilience and disaster planning in a region of high seismic risk? the case of the Southern Alps, New Zealand. 3500. https://doi.org/10.1080/13683500.2012.741115

Parnell, J. A. (2009). Crisis Management and Strategic Orientation in Small and Medium-Sized Enterprises ( SMEs ) in Peru, Mexico and the United States.

Pathak, S., \& Ene, I. (2017). Gendered approach towards disaster recovery? Experiences from 2011 floods in Pathumthani province, Thailand. 24(December 2016), 129-134. https://doi.org/10.1016/j.ijdrr.2017.06.007 
Pearson, C. M., \& Clair, A. (1998). Reframing Crisis Management. 23(1), 59-76.

Premaratne, S. P. (2001). Networks, resources, and small business growth? The experience in Sri Lanka.

Romme, G. (1997). Mapping the Landscape of Organizational Learning. 15(I), $68-78$.

Samantha, G. (2018). The Impact of Natural Disasters on Micro, Small and Medium Enterprises (MSMEs): A Case Study on 2016 Flood Event in Western Sri Lanka. Procedia Engineering, 212, 744-751. https://doi.org/10.1016/ j.proeng.2018.01.096

Sardana, G. D., \& Dasanayaka, W. S. B. (2013). Economic recovery from natural disaster: Spotlight on interventions in tsunami affected micro and SMEs in Sri Lanka's Galle district. Competitiveness Review, 23(4-5), 384-397. https://doi.org/10.1108/CR-03-2013-0032

Saunders, M. N. K., Gray, D. E., \& Goregaokar, H. (2014). SME innovation and learning: The role of networks and crisis events. European Journal of Training and Development, 38(1-2), 136-149. https://doi.org/10.1108/EJTD-07-20130073

Shrivastava, P. (1993). Organization \& Environment Crisis theory/practice? towards. https://doi.org/10.1177/108602669300700103

Simola, S. K. (2005). Organizational crisis management overview and opportunities. Consulting Psychology Journal, 57(3), 180-192. https://doi.org/10.1037/10659293.57.3.180

Simón, M. V., Revuelto, T. L., \& Ribeiro, S. D. (2016). Influence of economic crisis on new SME survival: reality or fiction? Entrepreneurship and Regional Development, 28(1-2), 157-176. https://doi.org/10.1080/ 08985626.2015 .1118560

Smith, D. (1990). Beyond contingency planning: Towards a model of crisis management. Organization \& Environment, 4(4), 263-275. https://doi.org/ $10.1177 / 108602669000400402$

Journal of Business Studies, 7(2)

$-40-$

2020 
Spillan, J., \& Hough, M. (2003). Crisis Planning in Small Businesses: European Management Journal, 21(3), 398-407. https://doi.org/10.1016/s02632373(03)00046-x

Sullivan-Taylor, B., \& Branicki, L. (2011). Creating resilient SMEs: Why one size might not fit all. International Journal of Production Research, 49(18), 5565-5579. https://doi.org/10.1080/00207543.2011.563837

Tibay, V., Miller, J., Chang-Richards, A., Egbelakin, T., Seville, E., \& Wilkinson, S. (2018). Business resilience: A study of Auckland hospitality sector. Procedia Engineering, 212(2017), 1217-1224. https://doi.org/10.1016/ j.proeng. 2018.01.157

Vargo, J., \& Seville, E. (2011). Crisis strategic planning for SMEs: Finding the silver lining. International Journal of Production Research, 49(18), 5619-5635. https://doi.org/10.1080/00207543.2011.563902

Wang, J. (2008). Developing Organizational Learning Capacity in Crisis Management. Advances in Developing Human Resources, 10(3), 425-445. https://doi.org/10.1177/1523422308316464 